\title{
Erratum
}

\section{Salinity Tolerance Daphnia magna and Potential Use for Estuarine Sediment Toxicity Tests}

\author{
G. S. Schuytema, A. V. Nebeker, T. W. Stutzman
}

National Health and Environmental Effects Research Laboratory, Western Ecology Division, U.S. Environmental Protection Agency, Corvallis, Oregon 97333, USA

Arch. Environ. Contam. Toxicol. (1997) 33(2): 194-198

In the above paper, all designations of conductivity measurements as millisiemens per meter $(\mathrm{mS} / \mathrm{m})$ should be changed to millisiemens per centimeter $(\mathrm{mS} / \mathrm{cm})$. 